\title{
Pelvic venous insufficiency: Lipid peroxidation levels in ovarian venous blood
}

\author{
Marina A. Darenskaya ${ }^{1, * \odot}$, Dmitriy A. Stupin ${ }^{1,2}{ }^{\circledR}$, Andrey A. Semendyaev $^{2}{ }^{\circledR}$, Sergey I. Kolesnikov $^{1 \oplus}$, \\ Andrey V. Shcherbatykh ${ }^{2}$, Konstantin S. Tolkachev ${ }^{2}{ }^{\circledR}$, Lyubov I. Kolesnikova ${ }^{1 \oplus}$
}

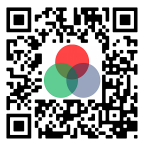

Use your smartphone to scan this QR code and download this article

${ }^{1}$ Scientific Centre for Family Health and Human Reproduction Problems, 16 Timiryasev str., Irkutsk, 664003, Russia

${ }^{2}$ Irkutsk State Medical University, 664022, Irkutsk, Russia

\section{Correspondence}

Marina A. Darenskaya, Scientific Centre for Family Health and Human

Reproduction Problems, 16 Timiryasev str., Irkutsk, 664003, Russia

Email: marina_darenskaya@inbox.ru

\section{History}

- Received: Dec 19, 2021

- Accepted: Feb 04, 2022

- Published: Feb 28, 2022

DOI : 10.15419/bmrat.v9i2.730

\section{Check for updates}

\section{Copyright}

(c) Biomedpress. This is an openaccess article distributed under the terms of the Creative Commons Attribution 4.0 International license.

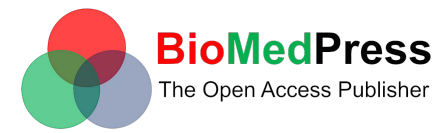

\begin{abstract}
Introduction: Pelvic venous insufficiency (PVI) presents a significant clinical challenge due to its high prevalence, severity of clinical manifestations, and risk of resulting reproductive disorders. Data suggests that PVI progression in women is accompanied by nonspecific reaction changes. The aim of this study was to evaluate lipid peroxidation reaction activity and antioxidant defense mechanisms in ovarian venous blood in patients with various stages of PVI. Methods: A total of 137 women of reproductive age with diagnosed PVI were separated into 3 subgroups (disease stages I, II, and III). The control group consisted of 30 women with overall good health. Blood sampling was performed in both groups of patients from the right and left pelvic ovarian veins. Spectrophotometry, spectrofluorometry, and enzyme immunoassays were used for investigation, and statistical analysis performed. Results: Patients with PVI stage I had higher levels of CDs and TBARs, as well as increased SOD, catalase, and GPO activity in both ovarian veins, compared to the control group. Patients with PVI stage II had higher LH, CDs, and TBARs, and reduced GSH in both ovarian veins compared to the control group. PVI stage III in the right and left ovarian veins was characterized by high levels of LH, CDs, and TBARs, and GSH deficiency (7 and 8.29 times lower, respectively) compared to the control group. There were no significant differences in these parameters between the right and left ovarian veins. Conclusion: Lipid peroxidation reaction activity and levels of antioxidant defense components in the right and left ovarian veins of patients with PVI demonstrate similar patterns across all stages of PVI. The imbalance between lipid peroxidation activity and antioxidant defense systems increases with disease progression from stage I to III. Monitoring changes in the LPO-AOD system in patients with PVI is an important component of preventive measures in the early stages of the disease, and could be used as pathogenetic treatment to limit disease progression.
\end{abstract}

Key words: Antioxidants, lipid peroxidation, pelvic venous insufficiency, women

\section{INTRODUCTION}

Pelvic venous insufficiency (PVI) presents a significant clinical challenge due to its high prevalence, the severity of its clinical manifestations (including venous congestion, which results in chronic pelvic pain syndrome), the high risk of resulting reproductive disorders (in $15-25 \%$ of patients), and the lack of treatment for persistent clinical effects ${ }^{\mathbf{1 , 2}}$. Age and hereditary predisposition, combined with other factors, are considered to be the main causes of morphofunctional changes in pelvic veins ${ }^{3,4}$. The disease follows a distinctive staged course, which determines the severity of the condition ${ }^{5}$. Disease onset is characterized by venous hypertension, venous valvular insufficiency, retrograde blood flow through the ovarian veins, and veno-venous discharge of the gonadal vein pool ${ }^{\mathbf{1 , 6}}$. The main components of PVI pharmacological therapy include improving venous flow, correcting microcirculatory disorders, and reducing inflamma- tory phenomena in the vessel walls and surrounding tissues $^{3,5-7}$.

Some data suggest that, in addition to hemodynamic disorders, PVI progression is associated with changes in nonspecific reactions, which are commonly involved in various destructive processes in tissues ${ }^{\mathbf{8 , 9}}$. Various biosubstrate free-radical oxidation reactions are thought to play an important role in this, particularly lipid peroxidation (LPO)-antioxidant defense (AOD) processes ${ }^{10-12}$. Only a few studies exist that are devoted to investigating this issue, and their results show that the influence of mechanisms of lipid peroxidation on varicose vein formation are fragmentary, and do not reflect changes in ovarian veins at the local level ${ }^{8,13}$.

The aim of this research was therefore to evaluate lipid peroxidation reaction activity and antioxidant defense mechanisms in ovarian venous blood in patients at various stages of PVI. 


\section{METHODS}

\section{Study design}

A total of 137 women (mean age $37.4 \pm 9.1$ years) with PVI were included in this study. PVI diagnosis was determined with an angioscan using duplex ultrasound ${ }^{\mathbf{1 4}}$. The following indicators were used for diagnosis: the maximum diameter of the lumen of the main venous trunk, the duration of reflux blood flow in the common trunk of the ovarian veins at rest, and the involvement of the small pelvic venous plexuses ${ }^{14,15}$. Women with PVI were separated into 3 groups according to disease stage (I, II, III). The control group consisted of 30 women without PVI (mean age $33.5 \pm 6.3$ years).

The inclusion criteria for patients with PVI were female gender, reproductive age, confirmed diagnosis of PVI, and informed consent for participation in the research. Exclusion criteria were the presence of a comorbid pathology, or pelvic gynecological or organic lesions. Inclusion criteria for the control group were as follows: age comparable with that of the case group, female gender, other basic criteria, absence of an acute disease or exacerbation of a chronic disease, and lack of venous system pathology. Exclusion criteria for both groups were as follows: use of medication with angioprotective, venotonic, or antioxidant effects, or intake of synthetic female sex hormones analogs within 6 months prior to this study. Pregnant patients were also excluded from this study.

\section{Ethical approval of research}

All women signed informed consent forms regarding participation in the research, in accordance with the World Medical Association Declaration of Helsinki (1964, 2013 ed.). The Ethics Committee (Scientific Centre for Family Health and Human Reproduction Problems) approved the research (No. 3.1 dated October 26, 2012).

\section{Biochemical measurements}

Blood sampling was performed from the right and left pelvic ovarian veins in patients with PVI and the control group during laparoscopy using equipment (Karl Storz, Germany and Cooper Surgical, USA) and a 3D Laser Optic System (USA, Germany) ${ }^{\mathbf{1 4}}$. Both plasma and erythrocyte hemolysate components were tested. The LPO activity intensity was determined from the levels of lipid hydroperoxides (LH), conjugated dienes (CDs) using spectrophotometry, and the levels of TBA-reactive products (TBARs) of LPO were measured using fluorometry ${ }^{16,17}$. The activity of the AOD system was determined by measuring the reduced glutathione (GSH) content ${ }^{18}$, and the activity of superoxide dismutase (SOD) ${ }^{19}$, catalase, glutathione reductase (GR), glutathione peroxidase (GPO), and glutathione-S-transferase (GST) was determined using commercial kits by Randox (UK). Measurements were made using the spectrofluorophotometer "Shimadzu RF-1501" (Japan) and the spectrophotometer "Shimadzu RF-1650" (Japan). Enzyme immunoassay was performed with a MultiSkan ELX808 microplate reader (Biotek, USA). The equipment used was from the Collective Usage Centre at the Center for the Development of Progressive Personalized Health Technologies.

\section{Statistical analysis}

Statistical analysis of the data was performed using the Statistica 8.0 package (StatSoft Inc., USA). The mean $(\mathrm{M})$ and standard deviation $(\sigma)$ were calculated for each value. The visual-graphic method and Kolmogorov-Smirnov test (Lilliefors and ShapiroWilk correction) were used to determine the normality of the distribution of the characteristics. Student's $t$ test (for normal distribution) or the Mann-Whitney test (for abnormal distribution) were applied. The critical level of significance was assumed to be $5 \%$ (0.05).

\section{RESULTS}

The clinical characteristics of the patients in the PVI and control groups are presented in Table 1. There were no statistically significant differences in the main characteristics $(\mathrm{p}>0.05)$.

Patients with PVI stage I showed statistically significant differences in several measurements in both the right and left ovarian veins, compared to the control group. In the right and left ovarian veins of PVI stage I patients, levels of CDs were higher by 1.33 times ( $p$ $=0.002)$ and 1.34 times $(\mathrm{p}=0.015)$, respectively; levels of TBARs were higher by 1.34 times and 1.33 times $(p=0.003)$, respectively; SOD activity was higher by 1.49 times $(\mathrm{p}<0.0001)$ and 1.7 times $(\mathrm{p}<0.0001)$, respectively; and GPO activity was higher by 1.72 times $(\mathrm{p}<0.0001)$ and 1.76 times $(\mathrm{p}=0.007)$, respectively, compared to the control group (Figure 1).

In patients with PVI stage II, significant differences were also noted in several measurements in both the right and left ovarian veins, compared to the control group. In the right and left ovarian veins of PVI stage II patients, levels of LH were higher by 1.39 times ( $p$ $=0.018)$ and 1.38 times $(\mathrm{p}=0.001)$, respectively; levels of CDs were higher by 1.68 times in both ( $p=$ 0.011 and $p=0.019$, respectively); levels of TBARs were higher by 1.35 times $(p=0.036)$ and 1.28 times $(\mathrm{p}=0.041)$, respectively; and GSH levels were lower 
Table 1: The clinical characteristics of the patients with PVI (n)

\begin{tabular}{lcccc}
\hline Characteristics & Control group & $\begin{array}{c}\text { I stage } \\
(\mathbf{n = 3 9 )}\end{array}$ & $\begin{array}{c}\text { II stage } \\
(\mathbf{n = 6 5})\end{array}$ & $\begin{array}{c}\text { III stage } \\
(\mathbf{n}=\mathbf{3 3})\end{array}$ \\
\hline Age mean & 38.6 & 32.5 & 37.8 & 42.6 \\
Hypertension & 2 & 1 & 7 & 12 \\
Obesity & 5 & 4 & 16 & 10 \\
Diabetes mellitus & 2 & 2 & 8 & 6 \\
Irregular menstruation & 8 & 9 & 25 & 18 \\
Pelvic pain & 5 & 21 & 50 & 27 \\
Dyspareunia & 3 & 10 & 18 & 12 \\
Infertility & 4 & 8 & 18 & 10 \\
Dysuria & 3 & 3 & 12 & 7 \\
Psycho-emotional disorders & 4 & 6 & 18 & 10 \\
Vein expansion lower limbs & 4 & 2 & 15 & 18 \\
Vulvar varicose veins & 1 & 2 & 8 & 13 \\
Disorders of pelvic organs function & 5 & 10 & 19 & \\
\hline
\end{tabular}

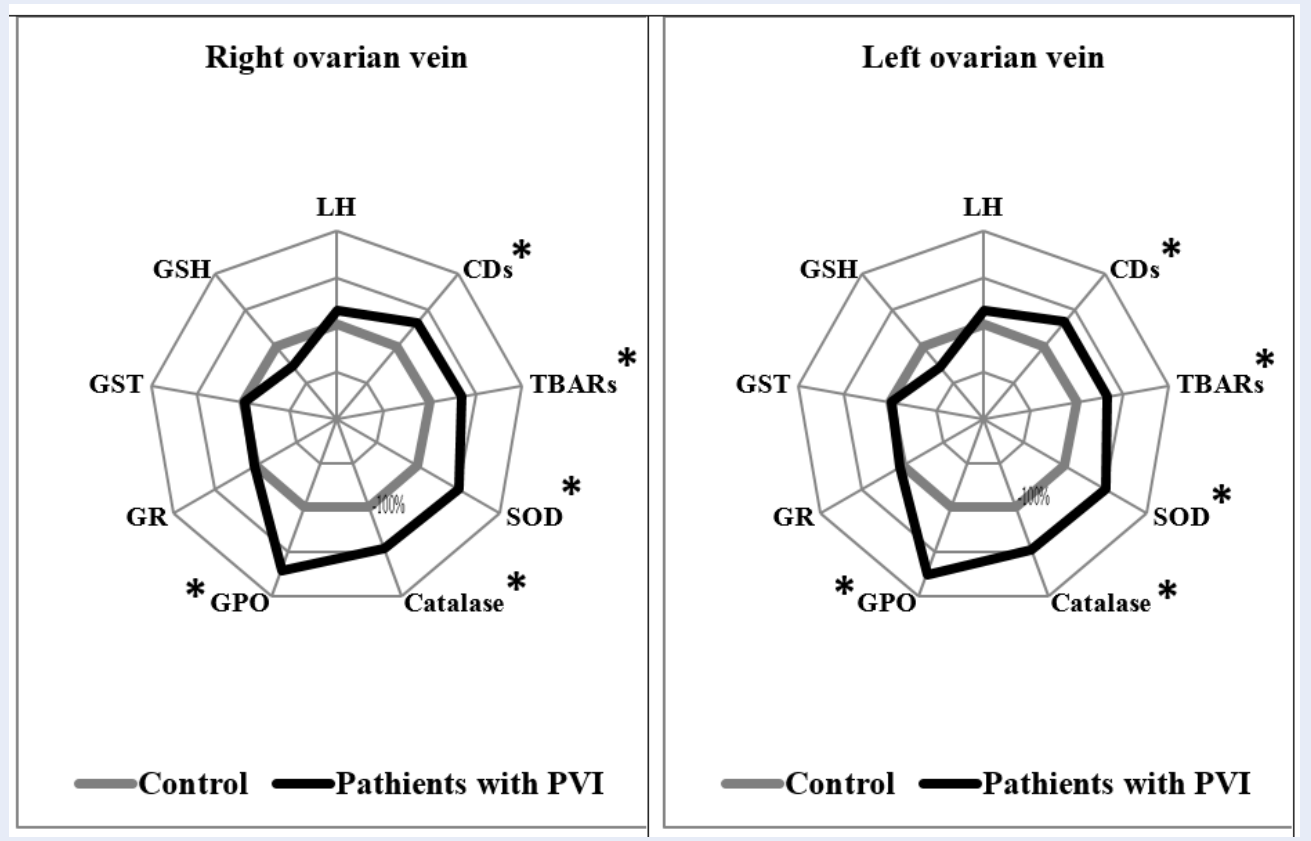

Figure 1: The lipid peroxidation products and antioxidant defense parameters in the right and left ovarian veins in women with I study of the primary PVI (*- statistically differences with control (as $100 \%)$ ). CDs: conjugated dienes; GR: glutathionereductase; GPO: glutathione peroxidase; GST: glutathione-S-transferase; GSH: reduced glutathione; LH: lipid hydroperoxides; PVI: pelvic venous insufficiency; SOD: superoxide dismutase; TBARs: thiobarbituricacid reactants. 


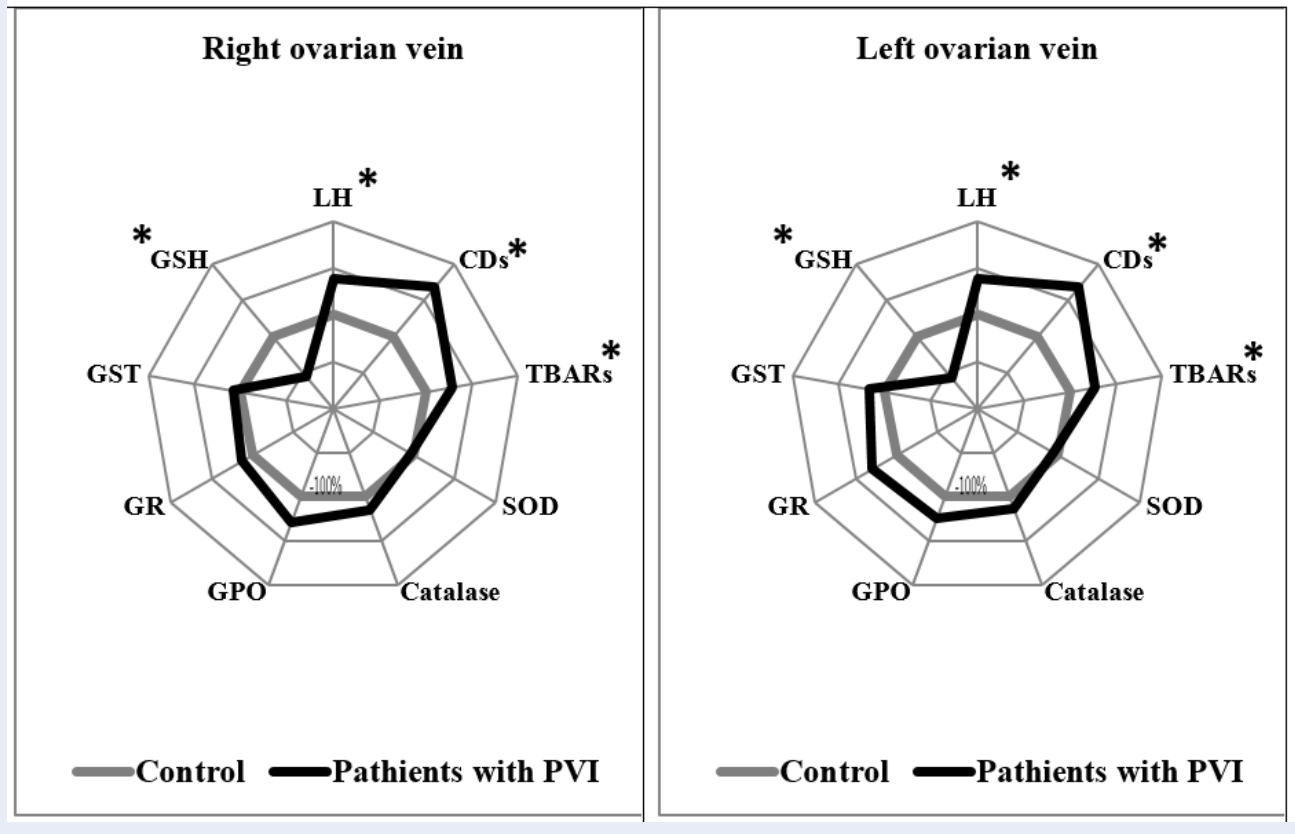

Figure 2: The lipid peroxidation products and antioxidant defense parameters in the right and left ovarian veins in women with II study of the primary PVI (*- statistically differences with control (as $100 \%)$ ). CDs: conjugateddienes; GR: glutathione reductase; GPO: glutathione peroxidase; GST: glutathione-S-transferase; GSH: reduced glutathione; LH: lipid hydroperoxides; PVI: pelvic venous insufficiency; SOD: superoxidedismutase; TBARs: thiobarbituric acid reactants.

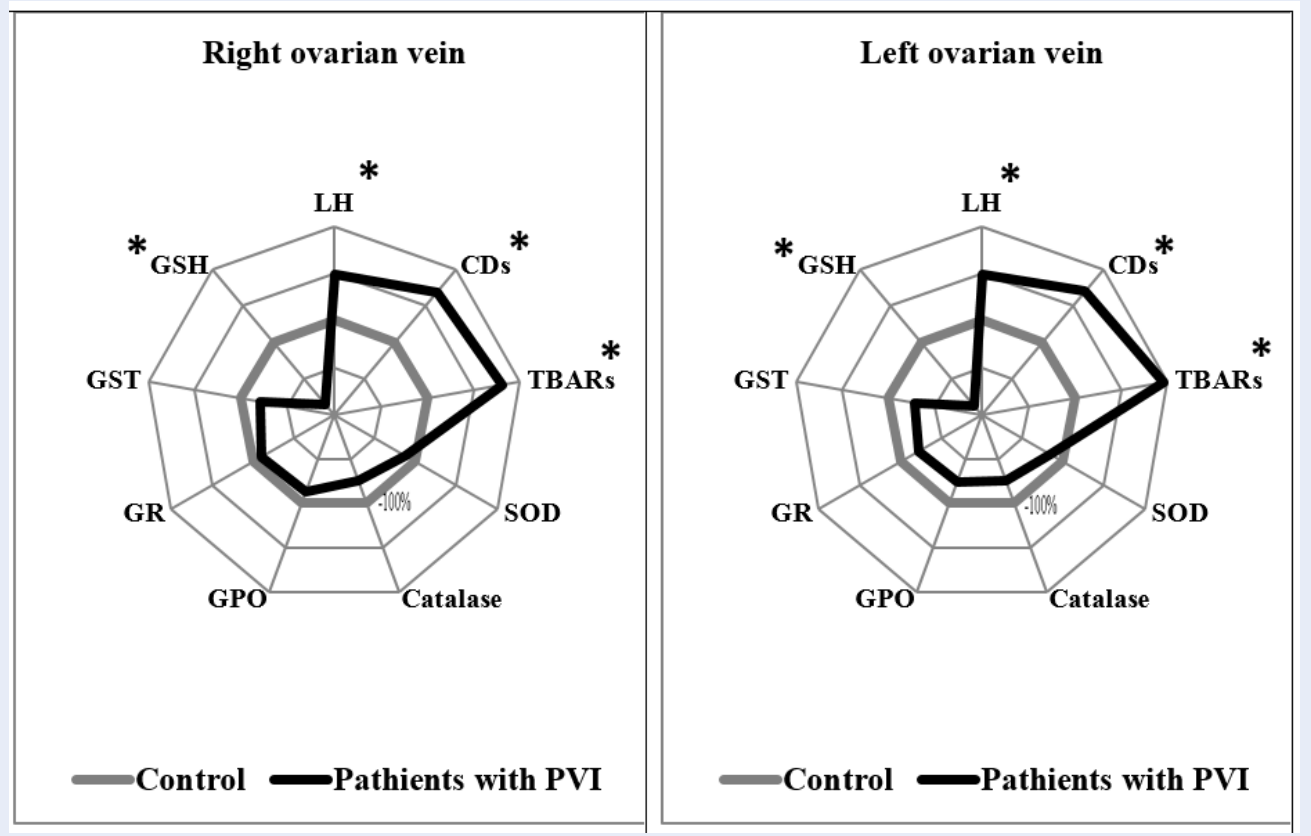

Figure 3: The lipid peroxidation products and antioxidant defense parameters in the right and left ovarian veins in women with III study of the primary PVI (*- statistically differences with control (as 100\%)). CDs: conjugated dienes; GR: glutathione reductase; GPO: glutathione peroxidase; GST: glutathione-S-transferase; GSH: reduced glutathione; LH: lipid hydroperoxides; PVI: pelvic venous insufficiency; SOD: superoxide dismutase; TBARs: thiobarbituric acid reactants. 
by 1.38 times ( $\mathrm{p}=0.028)$ and 2.34 times, respectively, compared to the control group (Figure 2).

Finally, patients with PVI stage III also had significant differences in measurements from both ovarian veins, compared to the control group. In the right and left ovarian veins of PVI stage III patients, levels of LH were higher by 1.48 times in both $(\mathrm{p}=0.031$ and $\mathrm{p}=$ 0.035 , respectively); levels of CDs were higher by 1.69 times $(\mathrm{p}<0.001)$ and 1.71 times $(\mathrm{p}<0.001)$, respectively; levels of TBARs were higher by 1.82 times ( $\mathrm{p}=$ $0.0001)$ and 1.96 times $(\mathrm{p}<0.001)$, respectively; and levels of GSH were lower by 7 times $(\mathrm{p}<0.0001)$ and 8.29 times ( $\mathrm{p}<0.0001)$, respectively, compared to the control group (Figure 3).

\section{DISCUSSION}

PVI is known to have a chronic course that is difficult to treat, and this is largely due to a wide variety of factors affecting the venous wall ${ }^{3,6,7}$. These factors include increased venous pressure, venous wall weakening as a result of atypical composition of the extracellular matrix, changes in venous tone, etc. ${ }^{\mathbf{1 , 6 , 7 , 2 0}}$. The ovarian vein (v. ovarica) begins in the area of the ovarian gate from a large number of veins exiting the gland $^{21}$. These veins form a plexus pampiniformis ovarii in the mesentery of the ovary. This plexus is located between the sheets of the uterine broad ligament, and anastomoses to the uterine venous plexus and fallopian tube veins. Plexus pampiniformis ovarii continues into the ovarian vein, which accompanies the artery of the same name. On the left, the ovarian vein flows into the left renal vein; on the right, however, the ovarian vein flows directly into the inferior vena cava. All pelvic venous plexuses anastomose with one other, and these anastomoses vary considerably in their flow capacity ${ }^{22}$. A number of studies have reported the significance of anatomy in PVI, which occurs frequently in the left ovarian vein ${ }^{23}$. Absence of venous valves in the upper part of the ovarian vein has been detected in up to $15 \%$ and $6 \%$ of cases on the left and right sides, respectively ${ }^{13}$.

Changes in the lipid peroxidation system serve as a significant factor in PVI development and progres-

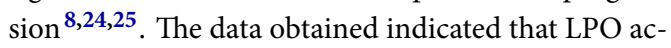
tivity increased as the AOD process decreased in the right and left ovaries, with increasing stages of PVI. It should be noted, however, that patients with PVI stage I had higher values of primary and secondary products of LPO activity, as well as compensatory increases in the activity of antioxidant enzymes SOD, catalase, and GPO, compared to the control group. These changes were observed in both ovarian veins relative to the controls, and no difference in parameters between veins was detected.

It has been established that the biological effects of free radicals are mediated through both their direct effects on protein amino groups, phospholipids, and nucleic acids, and also through effects on LPO products of the chain reaction ${ }^{26,27}$. Biomembrane deformation and changes in ion transport dynamics, enzyme activity, and other pathological phenomena are possible ${ }^{28}$.

Organisms have certain well-recognized defense mechanisms to prevent, eliminate, or partially reduce the synthesis of reactive oxygen species (ROS). The most significant limiting factor of the lipid peroxidation processes is the high activity of enzymatic antioxidant defense ${ }^{\mathbf{1 0}}$. SOD and catalase enzymes act as the first line of defense against ROS, and the increased activity of these enzymes observed in patients with PVI stage I may indicate the presence of compensatory mechanisms at the initial stage of the disease. GPOs are another family of enzymes that protect organisms from injury from ROS, and do so by catalyzing the reduction of lipid hydroperoxide to alcohols, and hydrogen peroxide to water ${ }^{28}$. GPO is oxidized to oxidized glutathione (GSSG), and is reduced by an $\mathrm{NADPH}$-dependent enzyme, $\mathrm{GR}^{29}$. In PVI stage I, we can suggest the adequate response of this enzyme to the increase in toxic products of lipid peroxidation. Previous studies have shown that levels of catalase and malondialdehyde increase in patients with varicose veins, whereas SOD, GPO, and GST activity show no statistically significant difference, which was described by the compensatory reaction ${ }^{8}$.

PVI stage II also showed a similar pattern of LPOAOD processes in the right and left ovarian veins, compared to the control. There was a pronounced imbalance in LPO product synthesis and the activity of AOD factors. In both veins, we noted high levels of lipid hydroperoxides, CDs, and TBARs, and decreased levels of GSH. Most LPO products are known to be toxic in excessive concentrations, and can have a destructive effect on cellular components. Lipid hydroperoxides are able to inhibit DNA synthesis, cell proliferation and growth, and have teratogenic and carcinogenic effects that induce mutations in cell DNA ${ }^{12}$. Studies have shown local congestive venous hemodynamics, hypoxia, decreased oxygen saturation, and ROS production are all factors that induce pathological changes in the pelvic veins of women $\mathbf{8 , 9 , 1 3}$. Tissue ischemia and endothelial dysfunction that result from varicose vein transformation can further enhance free-radical reactions, which leads to decreased organism resistance ${ }^{8}$. Leukocyte 
aggression in the inflammatory process aggravates vessel wall damage, which leads to the progression of venous framework integrity disorders ${ }^{4}$. Data has also shown that the intensification of peroxide processes results in the formation of dense lipofuscin structures, which impair the function of microcirculatory channels in many organs and tissues ${ }^{30}$. Thus, the activation of lipid peroxidation reactions during the pathological process in patients can aggravate morphofunctional disorders at the level of venous blood flow, and can contribute to further progression of the disease. In PVI stage III, we observed similar changes to PVI stage II, with lipid peroxidation reaction intensification and significant accumulation of final TBARs. In addition, a pronounced deficiency of the reduced form of glutathione was detected in both ovarian veins. Glutathione-dependent enzymes play a key role in the AOD system, the main component of which is the low-molecular-weight thiol gammaglutamylcysteinylglycine (GSH), which is the most common sulfhydryl compound in cells ${ }^{29}$. Its direct function is related to the maintenance of the active state of many enzymes, the spontaneous oxidation of which leads to disulfide group formation ${ }^{31}$. GSH is also the main antioxidant in erythrocytes, and serves as a coenzyme in the reduction of methemoglobin to the functionally active hemoglobin. It also detoxifies peroxides and hydroperoxides, which are formed by the reaction of ROS with unsaturated fatty acids in membranes ${ }^{31-33}$. The apparent deficiency of GSH can thus have a pronounced negative effect on the above processes.

It was not possible to comprehensively assess the state of the antioxidant defense system in patients with PVI, including the analysis of the content of the parameters of the nonenzymatic link - water and fatsoluble vitamins, the level of total antioxidant activity of the blood, etc., which is associated with additional financial costs for the implementation of this study.

\section{CONCLUSIONS}

Similar levels of lipid peroxidation reaction activity and antioxidant defense factors are observed in both left and right ovarian veins of PVI patients in all stages of the disease. As the disease progresses from stage I to III, an increase in lipid peroxidationantioxidant defense system imbalance is noted. Controlling changes in the lipid peroxidation-antioxidant defense system in PVI patients could be an important preventative measure in the early stages of the disease, and could contribute to pathogenetic treatment as it progresses.

\section{ABBREVIATIONS}

AOD: antioxidant defense, CDs: conjugated dienes, DNA: Deoxyribonucleic acid, GPO: glutathione peroxidase, GR: glutathione reductase, GSH: reduced glutathione, GST: glutathione-S-transferase, LH: lipid hydroperoxides, LPO: lipid peroxidation, M: mean, NADPH: nicotinamide adenine dinucleotide phosphate, PVI: Pelvic venous incompetence, ROS: reactive oxygen species, SOD: superoxide dismutase, TBARs: TBA-reactive products, $\sigma$ : standard deviation

\section{ACKNOWLEDGMENTS}

None.

\section{AUTHOR'S CONTRIBUTIONS}

Research concept and design: Marina A. Darenskaya, Dmitriy A. Stupin, Andrey A. Semendyaev, Konstantin S. Tolkachev; Collection and processing of material: Dmitriy A. Stupin, Andrey A. Semendyaev, Andrey V. Shcherbatykh; Text writing: Marina A. Darenskaya, Andrey A. Semendyaev, Sergey I. Kolesnikov

Editing: Sergey I. Kolesnikov, Lyubov I. Kolesnikova; Approval of the final version of the article: Sergey I. Kolesnikov, Lyubov I. Kolesnikova. All authors read and approved the final manuscript.

\section{FUNDING}

None.

\section{AVAILABILITY OF DATA AND MATERIALS}

Data and materials used and/or analyzed during the current study are available from the corresponding author on reasonable request.

\section{ETHICS APPROVAL AND CONSENT TO PARTICIPATE}

This study was conducted in accordance with the amended Declaration of Helsinki. The institutional review board approved the study, and all participants provided written informed consent.

\section{CONSENT FOR PUBLICATION}

Not applicable.

\section{COMPETING INTERESTS}

The authors declare that they have no competing interests. 


\section{REFERENCES}

1. Khilnani NM, Meissner MH, Learman LA, Gibson KD, Daniels JP, Winokur RS. Research Priorities in Pelvic Venous Disorders in Women: Recommendations from a Multidisciplinary Research Consensus Panel. Journal of Vascular and Interventional Radiology. 2019;30(6):781-9. PMID: 30857986. Available from: 10.1016/j.jvir.2018.10.008

2. Khatri G, Khan A, Raval G, Chhabra A. Diagnostic evaluation of chronic pelvic pain. Physical Medicine and Rehabilitation Clinics of North America. 2017;28(3):477-500. PMID: 28676360. Available from: 10.1016/j.pmr.2017.03.004.

3. Riding DM, Hansrani V, McCollum C. Pelvic vein incompetence: clinical perspectives. Vascular Health and Risk Management. 2017;13:439-47. PMID: 29225469. Available from: 10.2147/VHRM.S132827.

4. Castro-Ferreira R, Cardoso R, Leite-Moreira A, Mansilha A. The role of endothelial dysfunction and inflammation in chronic venous disease. Annals of Vascular Surgery. 2018;46(46):38093. PMID: 28688874. Available from: 10.1016/j.avsg.2017.06. 131.

5. Kistner RL, Eklöf B. Classification and etiology of chronic venous disease. In: Gloviczki P, editor. Handbook of venous disorders. 3rd ed. London: Hodder Arnold; 2009; 37-46. Available from: 10.1201/9781315382449.

6. Bendek B, Afuape N, Banks E, Desai NA. Comprehensive review of pelvic congestion syndrome: causes, symptoms, treatment options. Current Opinion in Obstetrics \& Gynecology. 2020;32(4):237-42. PMID: 32487799. Available from: 10.1097/GCO.0000000000000637.

7. Gregorio MAD, Guirola JA, Alvarez-Arranz E, Sánchez-Ballestin $M$, Urbano J, Sierre S. Pelvic venous disorders in women due to pelvic varices: treatment by embolization: experience in 520 patients. Journal of Vascular and Interventional Radiology. 2020;31(10):1560-9. PMID: 32855049. Available from: 10.1016/j.jvir.2020.06.017.

8. Saribal D, Kanber EM, Hocaoglu-Emre FS, Akyolcu MC. Effects of the oxidative stress and genetic changes in varicose vein patients. Phlebology. 2019;34(6):406-13. PMID: 30463472. Available from: $10.1177 / 0268355518814124$.

9. Donnez J, Binda MM, Donnez O, Dolmans MM. Oxidative stress in the pelvic cavity and its role in the pathogenesis of endometriosis. Fertility and Sterility. 2016;106(5):1011-7. PMID: 27521769. Available from: 10.1016/j.fertnstert.2016.07. 1075.

10. Kolesnikova LI, Darenskaya MA, Kolesnikov SI. Free radical oxidation: a pathophysiologist's view. Bulletin of Siberian Medicine. 2017;16(4):16-29. Available from: 10.20538/16820363-2017-4-16-29.

11. Darenskaya MA, Kolesnikov SI, Rychkova LV, Grebenkina LA, Kolesnikova LI. Oxidative stress and antioxidant defense parameters in different diseases: ethnic aspects. Free Radical Biology \& Medicine. 2018;120:60. Available from: 10.1016/j. freeradbiomed.2018.04.199.

12. Darenskaya MA, Grebenkina LA, Sholokhov LF, et al. Lipid peroxidation activity in women with chronic viral hepatitis. Free Radical Biology \& Medicine. 2016;100(S):S192. Available from: 10.1016/j.freeradbiomed.2016.10.525.

13. Kehinde BA, Abolhassani F, Yazdekhasti H, Abbasi N, Heydari $L$, Daneshi $E$. The effects of unilateral varicose ovarian vein on antioxidant capacity and oocyte quality in rat ovary. Iranian Journal of Basic Medical Sciences. 2016;19(8):863-9. PMID: 27746868.

14. Akhmetzyanov RV, Bredikhin RA, Fomina EE, Ignatyev IM. Method of determining disease severity in women with pelvic varicose veins. Angiologiia i sosudistaia khirurgiia (in Russian). 2019;25(3):79-87. Available from: 10.33529/ANGIO2019402.

15. Semendyaev AA, Stupin DA, Cherepanova MA, et al.. Method for determining the functional state of the venous system of the small pelvis in women. Patent RF № 2646563; 2018. (in Russian); 2018.
16. Volchegorskij IA, Nalimov AG, Jarovinskij BG, Lifshic RI. Comparison of different approaches to the determination of lipid peroxidation products in heptane-isopropanol extracts of blood. Voprosy medicinskoj himii (in Russian) . 1989;35(1):127-131.

17. Gavrilov VB, Gavrilova AR, Mazhul LM. Analysis of methods for determining the products of lipid peroxidation in blood serum by the test with thiobarbituric acid. Voprosy medicinskoj himii (in Russian) . 1987;1:118-122.

18. Hissin PJ, Hilf R. A fluorometric method for determination of oxidized and reduced glutathione in tissues. Analytical Biochemistry. 1976;74(1):214-26. PMID: 962076. Available from: 10.1016/0003-2697(76)90326-2.

19. Misra HP, Fridovich I. The role of superoxide anion in the autoxidation of epinephrine and a simple assay for superoxide dismutase. The Journal of Biological Chemistry. 1972;247(10):3170-5. PMID: 4623845. Available from: 10. 1016/S0021-9258(19)45228-9.

20. Khilnani NM, Winokur RS, Scherer KL, Meissner MH. Clinical Presentation and Evaluation of Pelvic Venous Disorders in Women. Techniques in Vascular and Interventional Radiology. 2021;24(1):100730. PMID: 34147196. Available from: 10.1016/j.tvir.2021.100730.

21. Szary C, Wilczko J, Zawadzki M, Grzela T. Hemodynamic and radiological classification of ovarian veins system insufficiency. Journal of Clinical Medicine. 2021;10(4):646. PMID: 33567554. Available from: 10.3390/jcm10040646.

22. Aikimbaev K, Balli TH, Akgul E, Aksungur EH. Ovarian vein diameters measured by MDCT in women without evidence of pelvic congestion syndrome. Heart. Vessels and Transplantation. 2017;1(2):43-8. Available from: 10.24969/hvt.2017.18.

23. Tinelli A, Prudenzano R, Torsello M, Malvasi A, Nunzio GD, Mitri ID. Suprapubic percutaneous sclero-embolization of symptomatic female pelvic varicocele under local anesthesia. European Review for Medical and Pharmacological Sciences. 2012;16(1):111-7. PMID: 22338556.

24. Nishijima S, Sugaya K, Kadekawa K, Ashitomi K, Ueda T, Yamamoto $\mathrm{H}$. Mechanisms underlying the effects of propiverine on bladder activity in rats with pelvic venous congestion and urinary frequency. Biomedical Research. 2019;40(4):145-52. PMID: 31413235. Available from: 10.2220/biomedres.40.145.

25. Xu Y, Zhang L, Shen Y, Yao H, Yong S, You Y. Effectiveness of psychological interventions for treating chronic prostatitis/chronic pelvic pain syndrome: A protocol for systematic review and meta-analysis. Medicine. 2020;99(39):e22151. PMID: 32991409. Available from: 10.1097/MD.0000000000022151.

26. Kolesnikova LI, Vlasov BY, Kolesnikov SI, Darenskaya MA, Grebenkina LA, Semenova NV. Intensity of oxidative stress in Mongoloid and Caucasian patients with type 1 diabetes mellitus. Bulletin of Experimental Biology and Medicine. 2016;161(6):767-9. PMID: 27783301. Available from: 10.1007/ s10517-016-3505-0.

27. Kolesnikova LI, Rychkova LV, Kolesnikova LR, Darenskaya MA Natyaganova LV, Grebenkina LA. Coupling of lipoperoxidation reactions with changes in arterial blood pressure in hypertensive isiah rats under conditions of chronic stress. Bulletin of Experimental Biology and Medicine. 2018;164(6):7125. PMID: 29658086. Available from: 10.1007/s10517-018-40643.

28. Bairova TA, Kolesnikov SI, Kolesnikova LI, Pervushina OA Darenskaya MA, Grebenkina LA. Lipid peroxidation and mitochondrial superoxide dismutase- 2 gene in adolescents with essential hypertension. Bulletin of Experimental Biology and Medicine. 2014;158(2):181-4. PMID: 25430642. Available from: $10.1007 /$ s10517-014-2717-4.

29. Calabrese G, Morgan B, Riemer J. Mitochondrial glutathione: regulation and functions. Antioxidants \& Redox Signaling. 2017;27(15):1162-77. PMID: 28558477. Available from: 10 1089/ars.2017.7121.

30. Niki E. Lipid peroxidation products as oxidative stress biomarkers. BioFactors (Oxford, England). 2008:34(2):171-80. PMID: 19706982. Available from: 10.1002/biof.5520340208. 
31. Adeoye O, Olawumi J, Opeyemi A, Christiania O. Review on the role of glutathione on oxidative stress and infertility. JBRA Assisted Reproduction. 2018;22(1):61-6. PMID: 29266896. Available from: 10.5935/1518-0557.20180003.

32. Darenskaya MA, Gavrilova OA, Rychkova LV, Kravtsova O, Grebenkina L, Osipova E. The assessment of oxidative stress intensity in adolescents with obesity by the integral index. International Journal of Biometrics. 2018;8(1):37-41. Available from: 10.21103/Article8(1)_OA5.

33. Minich DM, Brown BI. A review of dietary (phyto) nutrients for glutathione support. Nutrients. 2019;11(9):2073. Available from: $10.3390 /$ nu11092073. 
Ready to submit your manuscript? Choose Biomedpress and benefit from:

- Fast, convenient online submission

- Through peer-review by experienced researchers

- Rapid publication on acceptance

- Free of charge (without publication fees)

Learn more http://www.biomedpress.org/journals/
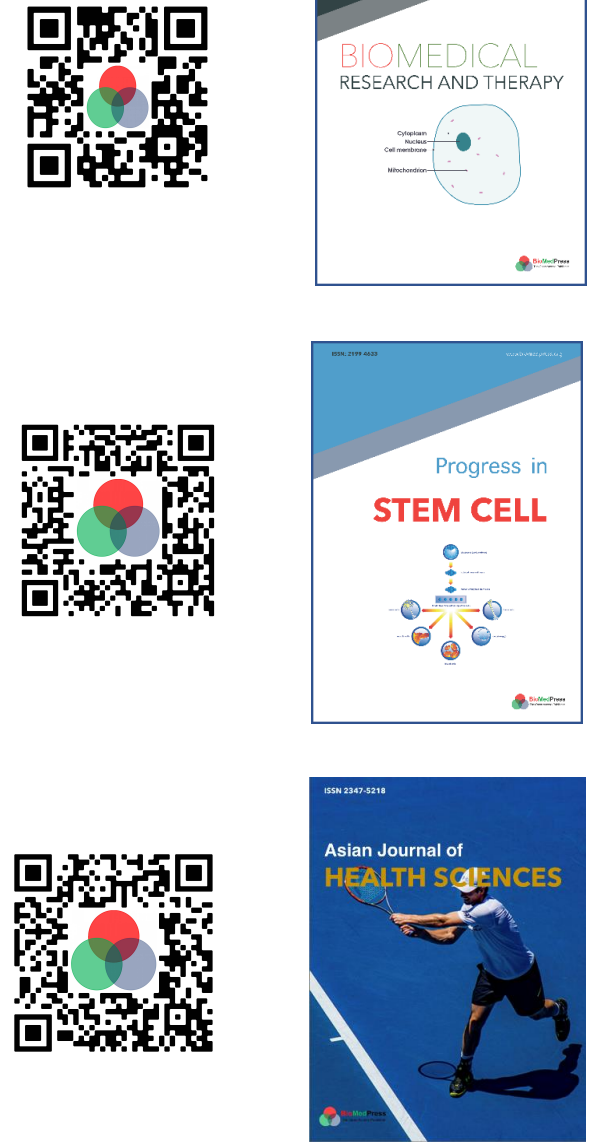

Asian Journal of Health Sciences

ISSN: 2347-5218

Indexed: Google Scholar

Acceptance Rate (2020): 72.89\%

Article Publishing Charge: Free

Submission to first editorial decision: 16.5 days

Biotechnological Research

ISSN: 2395-6763

Indexed: Google Scholar

Acceptance Rate (2020): $67.02 \%$

Article Publishing Charge: Free

Submission to first editorial decision: 28.5 days 